California Western School of Law

CWSL Scholarly Commons

Faculty Scholarship

2011

Protecting Scientific Integrity: The Commercial Speech Doctrine Applied to Industry Publications

Joanna K. Sax

California Western School of Law, jsax@cwsl.edu

Follow this and additional works at: https://scholarlycommons.law.cwsl.edu/fs

Part of the First Amendment Commons, and the Food and Drug Law Commons

Recommended Citation

Joanna K. Sax, Protecting Scientific Integrity: The Commercial Speech Doctrine Applied to Industry Publications, 37 AM. J.L. \& MED. 203 (2011).

This Article is brought to you for free and open access by CWSL Scholarly Commons. It has been accepted for inclusion in Faculty Scholarship by an authorized administrator of CWSL Scholarly Commons. For more information, please contact alm@cwsl.edu. 


\section{Protecting Scientific Integrity: The Commercial Speech Doctrine Applied to Industry Publications}

Joanna K. Sax, J.D., Ph.D.

\section{INTRODUCTION}

The pharmaceutical industry is a competitive business. Companies spend billions of dollars researching and developing new drugs. ${ }^{1}$ Many drugs never make it to market. For the limited drugs that make it through the experimental, regulatory, and clinical rigors of drug development, companies recoup their lost expenditures for the drugs that previously failed.

Pharmaceutical companies face increasing pressure to bring new treatments to market in order to survive. The economic reality of survival and profits may distort a company's decision-making process regarding full disclosure on a particular new drug. An example of this type of conflict was seen in the silicone breast implant fiasco in the 1970s, 1980s, and 1990s. Dow Corning, the manufacturer of the implants, withheld important data from long-term animal models that demonstrated adverse effects from the breast implants. $^{2}$ Further, Dow failed to conduct long-term studies on breast implants, even when armed with data indicating that such studies were necessary to ensure the continued health of the patients. ${ }^{3}$ Presumably, Dow stood to lose large sums of money if it conducted the long-term studies because it might establish the implants were harmful. It took litigation to expose Dow's failure to conduct the proper studies of the long-term effects of its implants.

\footnotetext{
${ }^{\dagger}$ Associate Professor of Law, California Western School of Law, 225 Cedar St., San Diego, CA 92101, (619) 515-1553, jsax@cwsl.edu; J.D. University of Pennsylvania Law School, Ph.D. University of Pennsylvania School of Medicine. The author thanks Michal Belknap, Larry Benner, Glenn Smith, and participants in the symposium for valuable comments and

${ }^{1}$ Frank Vinluan, Pharma Spending on REDD Nosedived in 2009, Study Finds, Triangle $\mathrm{J}$. (May 31 , 2010), http://www.bizjournals.com/triangle/stories/2010/05/31/story12.html ("R\&D spending among U.S. pharma companies last year declined by thirteen percent, to $\$ 17.2$ billion from $\$ 19.8$ billion in 2008.”).

${ }^{2}$ Hopkins v. Dow Corning Corp., 33 F.3d 1116, 1119 (9th Cir. 1994).

${ }^{3} I d$.
} criticisms. Bus. 
Pharmaceutical companies are experts in marketing their new drugs. To do this in the medical and scientific literature, companies will publish positive results of their clinical trials. ${ }^{4}$ They tend not, however, to disclose negative results of clinical trials in scientific publications, or they down-play the negative results. Further, pharmaceutical companies may suppress negative results, change design studies, or halt studies early if they think the results may not be positive. ${ }^{5}$ No regulation requires that industry publish negative results, and the scientific community, the public, and policymakers may never be aware of such negative results. ${ }^{6}$

Pharmaceutical companies expend enormous resources promoting new drugs. In addition to direct-to-consumer advertisements, they publish results in non-peer reviewed scientific/medical journals, host symposiums, and write multiple articles citing their own work. They use these tactics to flood the medical and scientific literature with positive information about their drug. This might not be so harmful if it were not often intertwined with strategies of suppressing negative results in clinical trials. That is, some of the publications are misleading because they only tell half the story - but the other half, i.e., the negative consequences from the drug, is not reported. This selective reporting causes harm because doctors may be misled into using an inferior or harmful treatment.

Part II of this article analyzes the publication tactics employed by some members of the pharmaceutical industry (hereinafter "industry") and explains how some of the publications promote misleading information. In recent years, an entire sector has arisen to assist in the publication and promotion of pharmaceutical drugs. This section also introduces the Lanham Act, which prohibits false advertising. Claims against some industry tactics may be brought under the Lanham Act.

It is unclear, however, whether the Lanham Act can adequately address the issues with biased or misleading industry publications. For this reason, Part III proposes policy recommendations to require accurate dissemination

\footnotetext{
${ }^{4}$ See, e.g., Mark Friedberg et al., Evaluation of Conflict of Interest in Economic Analyses of New Drugs Used in Oncology, 282 JAMA 1453, 1453 (1999) ("Similarly, a study of clinical trial publications determined that there was a significant association between positive results in general internal medicine clinical trials and funding from a pharmaceutical manufacturer.") Of note, the Friedberg study was funded by an unrestricted grant from Amgen, Inc., which had a contractual right to review and comment on the manuscript and abstract prior to publication. See also Sameer S. Chopra, Industry Funding of Clinical Trials: Benefit or Bias?, 290 JAMA 113, 113 (2003) ("Research supported by pharmaceutical companies may also be subject to methodological bias. Industry funded clinical trials and cost-effectiveness analyses, for instance, yield positive results far more often than studies that are funded or conducted by other entities.").

${ }^{5}$ See Chopra, supra note 4, at 113 ("Numerous industry-sponsored trials, for example, are prematurely terminated for financial rather than for scientific or ethical reasons.").

${ }^{6}$ In 2007 , Congress expanded the use of a trial registry data bank that requires the registration of clinical trials for life-threatening conditions. Food and Drug Administration Amendments Act, Pub. L. No. 110-85, § 801, 121 Stat. 823, 904-22 (2007) [hereinafter FDAAA] (amending 42 U.S.C. $\$ 282$ ). This is a limited regulation that does not encompass all the past and ongoing studies conducted by the pharmaceutical companies. See also Clinicaltrails.gov Fact Sheet, NaT'L Insts. of Health, http://www.nlm.nih.gov/pubs/factsheets/clintrial.html (last updated Sept. 15, 2009) (The legislation requires the Department of Health and Human Services, through the NIH, to establish a registry of clinical trials for both federally and privately funded trials "of experimental treatments for serious or life-threatening diseases or conditions.”).
} 
of the results of clinical trials in order to protect scientific integrity and the public welfare. As previously called for by me and others, a national registry of all clinical trials would provide, in part, the needed transparency. The reader of any publication reporting the results of a clinical study could cross-check the accuracy of the data with a national registry. Another recommendation is to enact a regulation called the Truth in Marketing (TIM) Act. The TIM Act's policy objectives would expand the Food and Drug Administration's (FDA) current regulatory authority to penalize pharmaceutical companies for false or misleading direct-to-consumer advertising by including regulation of indirect-to-consumer marketing, such as publications in scientific journals. In addition, the TIM Act would provide for a private cause of action so that individuals and groups can bring claims against pharmaceutical companies for false or misleading publications found in scientific journals. The private cause of action would be limited to claims against a party that has a profitseeking motive, thus traditional academic hypotheses would not be impacted by this regulation. In essence, the TIM Act is a combination and extrapolation of the Lanham Act and other FDA programs, but the focus is on indirect-toconsumer marketing by the pharmaceutical industry.

An obvious defense on the part of industry to anything resembling the TIM Act is that their speech is fully protected by the First Amendment. Part IV of this article addresses whether industry publications are fully protected scientific speech or less fully protected commercial speech, and it concludes that the industry publications fall within the latter category. This section also analyzes whether the publications are misleading, which ends the inquiry there, or whether it is necessary to enact regulations that appropriately protect the public interest in sound science. This part concludes that no current federal regulation addresses these misleading or biasing industry tactics in a sufficient manner, and again stresses the need for a regulation such as the TIM Act.

\section{MISLEADING INDUSTRY PUBLICATIONS}

The pharmaceutical and biotechnology companies publish components of their research in a variety of medical and scientific journals in order to promote their companies' product(s). Previous studies demonstrate that industry publications have a bias in that they tend to report positive results of clinical trials. ${ }^{7}$ This is not surprising because industry has a profit-seeking motive and companies are likely to closely monitor the progress and process of a research study in such a way that adverse results may be suppressed leading to the publication of biased results. ${ }^{8}$

This bias does not exist-or at least not to the same extreme-in publications by academic laboratories that receive public funding. This is most likely due, in part, to the culture of academic science and the process of

${ }^{7}$ Friedberg et al., supra note 4, at 1455 ("Studies funded by pharmaceutical companies were nearly 8 times less likely to reach unfavorable qualitative conclusions than nonprofitfunded studies and 1.4 times more likely to reach favorable qualitative conclusions.”).

${ }^{8}$ Wendy Wagner \& David Michaels, Equal Treatment for Regulatory Science: Extending the Controls Governing the Quality of Public Research to Private Research, 30 AM. J.L. \& MED. 119, 120 (2004). 
peer review. Academic scientists publish results of their studies to communicate with other scientists in an attempt to collaboratively advance science. While most academic scientists publish positive results of experiments, a lot can be learned from results that are negative or not statistically significant. It is similar to the old adage-don't reinvent the wheel. Once a study has failed, there is value in communicating the results so that another laboratory does not waste time or resources only to find a dead end. It must be noted that even in the academic realm, there is a dearth of publications of negative results.

\section{A. Publishing Tactics}

This article focuses on industry's ability to manipulate scientists, physicians and ultimately the public through the publication of misleading studies. Some members of industry employ tactics to promote their studies, such as paying companies to find placements, hosting their own symposiums, publishing the same results in multiple journals, using ghost-authors and publishing results by paying to be placed in corporate-sponsored publications. ${ }^{9}$ Furthermore, there is a significant association between the reporting of positive results in a clinical trial of a new drug or treatment and funding from a pharmaceutical manufacturer. ${ }^{10}$ For example, Mark Friedberg and colleagues conducted a study to determine whether "pharmaceutical company-funded economic studies are more likely than nonprofit-funded studies to report favorable qualitative assessments and less likely to report unfavorable qualitative assessments." 11 This study concluded that "[s]tudies funded by pharmaceutical companies were nearly 8 times less likely to reach unfavorable qualitative conclusions than nonprofit-funded studies and 1.4 times more likely to reach favorable qualitative conclusions." ${ }^{12}$ The study also

${ }^{9} I d$. at 125 ("Some sponsors, for example, have been caught publishing the same study in different journals under different author names with no cross-references, making it appear that the research support in favor of their product or activity is based on several independent studies, rather than simply a re-reporting of the same findings"); see Sergio Sismondo, Ghost Management: How Much of the Medical Literature is Shaped Behind the Scenes by the Pharmaceutical Industry?, 4 PLoS MED. 1429, 1429 (2007) ("In extreme cases, drug companies pay for trials by contract research organizations (CROs), analyze the data in-house, have professionals write manuscripts, ask academics to serve as authors of those manuscripts, and pay communication companies to shepherd them through publication in the best journals. The resulting articles affect conclusions found in the medical literature, and are used in promoting drugs to doctors"); see also Richard Smith, Conflicts of Interest: How Money Clouds Objectivity, 99 J. Royal Soc'y MED. 292, 293 (2006) ("In fact, the only factor associated with the review's conclusion was whether the author was affiliated with the tobacco industry. Three-quarters of the articles concluding that passive smoking was not harmful were written by tobacco industry affiliates" (citation omitted)).

${ }^{10}$ See Friedberg et al., supra note 4, at 1453; Smith, supra note 9, at 293 ("The JAMA review found 11 studies that compared the outcome of studies sponsored by industry and those not so sponsored. In every study those that were sponsored were more likely to have a finding favourable to industry" (internal citation omitted)); see also Sismondo, supra note 9, at 1429.

${ }^{11}$ See Friedberg et al., supra note 4, at 1453.

12 See id. at 1455. A number of reasons may account for this. For example, the pharmaceutical company may be more likely to conduct clinical trials based on highly positive initial studies. Another reason, however, could be that pharmaceutical companies may want to control what is published and simply decide not to publish negative results. These, and other reasons, are suggested in the study conducted by Friedberg and colleagues. 
found that the qualitative statements were actually overstatements of quantitative results. ${ }^{13}$

An entire industry is dedicated to helping pharmaceutical and biotechnology companies place their publications in journals, which can have a considerable influence on medical research. ${ }^{14}$ For example, one company named Current Medical Directions (CMD) assists pharmaceutical companies with the publication of articles. ${ }^{15}$ Although the full range of services offered by companies such as CMD is unclear, it appears that CMD may help pharmaceutical companies place articles in higher-ranked journals, find academics to ghost-author articles, and assist in garnering citations to the particular article. ${ }^{16}$ All of these tactics increase exposure to the results of the particular study.

The use of these types of commercial tactics to publish articles is antithetical to the academic and scientific process of publication, which uses a peer review system to advance paradigms or argue for paradigm shifts. Scientific integrity is protected, in part, by the review of submitted research articles by scientific peers. The scientists review articles to determine whether the conclusions are valid based on the experiments, whether the proposed articles advance scientific understanding, and whether additional experiments are needed to prove the authors' conclusions. Instead of subjecting themselves to peer review, some members of industry will skirt around this system by creating their own publications, such as symposium issues, which allows them to promote their products without having the academic and scientific community review the research prior to publication. Even if a company submits its findings to a peer reviewed journal, studies show that privatelyfunded clinical trials report a bias in favor of their results, such that even the peer reviewers may not know if other data exists to temper the statements regarding the positive results. In these ways, industry can flood the scientific press with articles about their products.

A problem arises when the industry publications mislead the readers as to the conclusions in the paper. ${ }^{17}$ To illustrate this problem, the following hypothetical will be referred to throughout this article:

\footnotetext{
${ }^{13}$ See id.

${ }^{14}$ Sismondo, supra note 9, at 1429; see also MaryAnn Foote \& Philip David Noguchi, Posting of Clinical Trials and Clinical Trial Results: Information for Medical Writers, 20 Aм. MED. Writers Ass'N 47, 47 (2005) (informing medical writers who work for drug sponsors of the new rules regarding the reporting of clinical trials).

${ }^{15}$ Sismondo, supra note 9, at 1430; see also Our Work, Current Medical Directions, http://www.cmdny.com/work.html (last visited Apr. 10, 2011)

${ }_{16}$ Sismondo, supra note 9, at 1430 ("[T] prominent journals, had nearly twice as many authors per article, and garnered nearly three times as many citations.”).

${ }^{17} \mathrm{Cf}$. Wagner \& Michaels, supra note 8, at 122 ("At the same time that privately sponsored research provides a critical input to regulation, there is growing evidence that it can be compromised in ways that might underreport or even suppress evidence of harm. Sponsors face strong incentives to design and report research in ways most favorable to their interests and to suppress adverse results provided they can do so without detection.").
} 
Working Hypothetical: A company has an experimental medicine to treat high cholesterol. In a clinical trial, the company learns that its drug shows better results than the current standard therapy after six months of treatment. The company, however, also learns from this clinical study that after twelve months of treatment, there is no difference between the company's new drug and treatment with standard therapy. ${ }^{18}$ Since the twelvemonth results are not helpful to the company to promote the product, the company may decide to suppress the twelve-month time point and only publish the results of the first six months of the study.$^{19}$ Here, the company publishes the article in a non-peer reviewed journal. The company then writes several other articles citing its original article. Further, the company publishes a review article of drugs on the market for treatment of high cholesterol and highlights its own drug. The company then sends the review article to policymakers in Washington, D.C. to be used to support policies concerning the public health. In addition, the company promotes its product by sending reprints of its article to clinicians-in an effort to tell them that the company's new product is better than the standard treatment that these clinicians are currently prescribing to their patients.

All of these activities promote misleading or biased information because the company knows that there is no difference after one year between their new drug and the standard therapy. But by failing to include this information, the public, politicians, and clinicians may have no idea. Put differently, the publication may be accurate or truthful with respect to the data gathered at the six-month time-point, but the publication gives a false impression, via omission, that no other data was collected or that no other data exists to provide support for a contrary conclusion..$^{20}$ Plus, the public, politicians, scientists, and clinicians have almost no way to confirm or deny the data.

The hypothetical described above is reminiscent of the breast implant fiasco in the 1970s, 1980s, and 1990s. Although not a perfect analogy, the Dow case highlights the problem when a private company suppresses information

${ }^{18}$ The FDA may approve this drug to treat high cholesterol if the results demonstrate that the new drug is safe and effective. This is so, even if, for example, the new drug does not offer benefits beyond the standard treatment.

${ }^{19}$ Cf. Wagner \& Michaels, supra note 8, at 126 ("Finally and perhaps most serious is the ability of sponsors to suppress research when the results are adverse to their interests. Unlike fraud, suppressing adverse results can sometimes be done with discretionary judgments that are not illegal. For example, sponsors can abort research before it is completed, and base this decision on limited resources or some purported design flaw in the study. For research that is completed, sponsors can still justify withholding the results based on discretionary judgments that the research design or reporting was incomplete or flawed in some way or that follow-up research is needed to confirm or validate the findings." (citations omitted)).

${ }^{20}$ See Catherine DeAngelis, The Influence of Money on Medical Science, 296 JAMA 996, 996 (2006) ("There have been a number of high-profile examples of such research irregularities involving for-profit companies, such as . . . reporting only 6 months of data in a trial designed to have 12 months of data as the primary outcome . ..."); Chopra, supra note 4 , at 114 ("Bias may also occur in the reporting of industry-funded clinical trials. Withholding the publication of unfavorable results, for example, is not uncommon although the practice is considered scientific misconduct.”). 
or fails to follow-up on preliminary data. At issue in Hopkins v. Dow Corning Corp. was whether Dow was liable for a variety of health problems associated with its silicone gel breast implants. ${ }^{21}$ Dow denied liability, but the evidence demonstrated that Dow had knowledge of the harmful effects of the breast implants and that it suppressed these findings. ${ }^{22}$ Dow previously conducted animal model studies and learned that after six months the implants were fine, but that after two years the animals experienced an immune reaction around the implants. ${ }^{23}$ Dow did not publish these results for years, and when they did finally release the results they omitted the negative findings, which had the consequence of misleading the public to believe that the implants were safe. ${ }^{24}$ On top of this, the animal models and other studies should have made it clear to Dow that it needed to conduct long-term studies, but Dow did not. ${ }^{25}$ Presumably, Dow did not want to learn the results of long-term clinical studies because they might show that the breast implants were harmful. Both the failure to report the animal studies, and the failure to conduct additional studies misled the public into believing that Dow's breast implants were safe, though they were not.

The working hypothetical above addresses the publication of misleading information. Previous work analyzes the failure of the pharmaceutical industry to publish negative results of clinical trials. ${ }^{26}$ This previous work described that pharmaceutical companies failed to report or failed to study anecdotal reports of the treatment of children with antidepressant drugs leading to suicidal behaviors in teenagers. Congress held hearings to address industry's failure to conduct appropriate clinical studies in teenage populations. ${ }^{27}$ The failure by some members of industry to publish negative results from clinical trials or to follow-up on anecdotal information led, in part, to hiding the negative effects of anti-depressants in children. ${ }^{28}$ In short, the omission or hiding of negative data misled the medical world, which impacted the public. If this story seems similar to the breast implant case, that is because it is.

A variety of problems stem from the failure to report negative results, or only to report positive results, even when the company is aware of negative results. ${ }^{29}$ The first problem is the potentially widespread dissemination of these results. This may attract the popular press, which may pick up on an industry publication with misleading results and report it to a wide audience. Using the working hypothetical posed above, a New York Times reporter may write a story reporting that studies with a new cholesterol drug demonstrate better results than the standard treatment. A media storm may influence patients to request the new drug. Physicians may end up prescribing this new

\footnotetext{
${ }^{21}$ Hopkins v. Dow Corning Corp., 33 F.3d 1116, 1118 (9th Cir. 1994).

${ }^{22}$ Id. at 1119 .

${ }^{23} I d$.

${ }^{24} I d$.

${ }^{25} \mathrm{Id}$. at 1127 .

${ }^{26}$ Joanna K. Sax, Reforming FDA Policy for Pediatric Testing: Challenges and Changes in the Wake of Studies Using Antidepressant Drugs, 4 Ind. Health L. Rev. 61, 71-75 (2007).

${ }^{27} \mathrm{Id}$. at 75 .

${ }^{28} I d$. at 75 .

${ }^{29} C f$. DeAngelis, supra note 20, at 996 ("In some instances, the marketing goal of a company dominates the scientific aspect of the company-funded research.").
} 
drug. And all of this occurred because the company published the partial results of a clinical trial in a non-peer reviewed journal.

Second, reporting studies with misleading information, despite evidence to the contrary, may lead scientists on a dead-end chase. ${ }^{30}$ Using our working hypothetical, we could assume that the company's new drug uses a different biochemical pathway than the standard treatment. A scientist may see the multiple reports and review article promoted by the company including the data that the new drug provides more effective treatment than standard therapy. It turns out that the new drug uses a different biochemical pathway than the standard treatment. The scientist may begin conducting experiments to analyze the drug's biochemical properties in this new pathway. The problem is, however, that the new drug is not better than standard treatment after one year, and through the misleading publication, the company is, in effect, stonewalling scientific progress. Time, energy, and money may be wasted.

The third problem is the potential for the misleading publications to influence policy decisions. If the company promotes its misleading study by communicating it to policymakers, then the policymakers might rely on flawed, biased, or even untrue information. That is, policymakers would be using inappropriate information to create policy. ${ }^{31}$ Finally, misleading industry publications stifle scientific progress and chip away at the public's trust in scientists. ${ }^{32}$ In sum, misleading industry publications threaten scientific integrity.

The tobacco industry's use of propaganda in the 1960s and 1970s is an example of the parade of evils described above. During those two decades, the tobacco industry refuted evidence of harmful effects of second-hand smoke. ${ }^{33}$ The tobacco industry flooded the scientific literature with studies that concluded that passive smoking was not harmful. ${ }^{34}$ The tobacco industry did this by publishing articles in non-peer reviewed journals, publishing their own articles, and writing letters to the editor in medical journals. ${ }^{35}$ The majority of articles that concluded that passive smoking was not harmful were written by

${ }^{30} C f$. Heidi Ledford, Diabetes Drugs Offered Fresh Start, 466 Nature 420, 420 (2010) ("Since Avandia (rosiglitazone) hit the market, he [Steven Nissen] said, developers have wasted their time on at least 50 other drugs that act by a similar mechanism. All of them failed, Nissen said, some because they posed similar risks to the heart.").

${ }^{31}$ Wagner \& Michaels, supra note 8, at 121.

${ }^{32}$ See also Catherine D. DeAngelis, Phil B. Fontanarosa, \& Annette Flanagin, Reporting Financial Conflicts of Interest and Relationships Between Investigators and Research Sponsors, 286 JAMA 89, 90 (2001) ("Moreover, this level of involvement and control of the research could be viewed as the sponsor having the potential to influence the study results and might create doubts about the validity of the research. These concerns are not without foundation; previous reports have documented several major problems in some industrysponsored studies, including issues related to trial design, data availability, and control over publication." (internal citations omitted)).

${ }^{33}$ See Lisa A. Bero, Tobacco Industry Manipulation of Research, 120 Pub. Health ReP. 200, 200-01 (describing strategies utilized by the tobacco industry to manipulate the research on the harmful effects of smoking).

${ }^{34}$ See id. at 202-03 ("The tobacco industry uses several vehicles to publish the findings of its sponsored research, including symposium proceedings, books, journal articles, and letters to the editor in medical journals”); Smith, supra note 9, at 293.

${ }^{35}$ Bero, supra note 33, at 202-03. 
the tobacco industry and its affiliates. ${ }^{36}$ To give credibility to its own research, the tobacco industry then cited its own publications in non-peer reviewed publications and in policy arenas. ${ }^{37}$ The tobacco industry also wrote review articles, citing their own work. ${ }^{38}$ Policymakers often rely on review articles because they are supposed to provide a summary of the most up-to-date data. ${ }^{39}$ Another tactic utilized included suppressing or criticizing research that did not support the tobacco industry's position. ${ }^{40}$ The tobacco industry used numerous tactics to mislead policymakers and the public for decades. It took decades of research and education to overcome the strength of the tobacco industry's lobbying efforts to finally inform the public and policymakers of the harmful effects of second-hand smoke.

\section{B. Regulating Misleading Publications}

Industry publications that fail to report negative results may or may not be subject to the Lanham Act ${ }^{41}$ which applies to false advertising claims. ${ }^{42}$ While each state may have its own version of statutes designed to prohibit false advertising, this article will focus on the federal statute. 15 U.S.C. § 1125(a)(1)(B) provides that anyone who:

in commercial advertising or promotion, misrepresents the nature, characteristics, qualities, or geographic origin of his or her or another person's goods, services, or commercial activities, shall be liable in a civil action by any person who believes that he or she is or is likely to be damaged by such act. ${ }^{43}$

Arguably, any patient or member of the public who thinks they might be damaged by misleading industry publications that fail to fully disclose information about a particular drug or treatment may decide to bring a claim against the company publishing such article.

To establish a claim under this provision of the Lanham Act, a plaintiff must prove five elements:

${ }^{36}$ Smith, supra note 9, at 293 ("Three-quarters of the articles concluding that passive smoking was not harmful were written by tobacco industry affiliates.”).

${ }^{37}$ Bero, supra note 33, at 202.

${ }^{38} \mathrm{Id}$. at 203.

${ }^{39} I d$.

${ }^{40} I d$. at 204.

${ }^{41}$ The reason that the industry publications may not be subject to the Lanham Act is if the publications in journals are not considered "commercial advertising or promotion." Lanham Act, 15 U.S.C. $\$ 1125(\mathrm{a})(1)$ (B) (2006).

${ }^{42} 15$ U.S.C. $\$ 1125(\mathrm{a})$.

${ }^{43} 15$ U.S.C. $\$ 1125(a)(1)(B)$. 
(1) A false statement of fact by the defendant in a commercial advertisement about its own or another's product; (2) the statement actually deceived or has the tendency to deceive a substantial segment of its audience; (3) the deception is material, in that it is likely to influence the purchasing decision; (4) the defendant caused its false statement to enter interstate commerce; and (5) the plaintiff has been or is likely to be injured as a result of the false statement, either by direct diversion of sales from itself to defendant or by a loss of goodwill associated with its products. ${ }^{44}$

Applying the facts from our working hypothetical concerning the cholesterol study, a plaintiff may establish the elements in the following way: (1) A false statement in a publication by the pharmaceutical company that the new drug is better than standard treatment by only showing the first six months of data; (2) the statement has a tendency to deceive a physician in prescribing the drug to a patient or to deceive a patient by leading the patient to request the new drug to treat high cholesterol; (3) the false statement is likely to influence the decision to prescribe the new drug; (4) the defendant placed its study in interstate commerce by publishing its data; and (5) the plaintiff is likely to be injured because the plaintiff may have wasted time or money on a treatment that does not provide better results over the long term compared to the standard treatment and may even have different or worse side-effects. ${ }^{45}$ Thus, a plaintiff may be able to bring a cause of action for false advertising.

A central problem with a claim under the Lanham Act is that a publication in a medical or scientific journal may not meet the definition of "commercial advertising or promotion"-a required element under the Lanham Act. ${ }^{46}$ "Advertisement" is defined as "a public notice; especially: one published in the press or broadcast over the air." 47 Even though the pharmaceutical company may have an economic interest in promoting a drug through scientific publications, this may be different than the direct-toconsumer advertising that is usually governed under the Lanham Act. In addition, even if the Lanham Act may be available, the Lanham Act is not specific to concerns related to health and safety.

In specific circumstances, other federal statutes may be available that are specific to public health and safety. For example, the Food and Drug Administration Amendments Act (FDAAA) of 2007 reauthorized the Pediatric Research Equity Act and the Best Pharmaceuticals for Children Act

${ }^{44}$ United Indus. Corp. v. Clorox Co., 140 F.3d 1175, 1180 (8th Cir. 1998).

${ }^{45}$ This is a simplified explanation of establishing a claim. These types of claims are broken down further into commercial claims that are literally false and claims that may be literally true, but convey a false impression. $I d$. Depending on the type of misleading industry publication, claims may fall under one category or the other. See William H. Manning \& Jennifer L. McKenna, Lanham Act Also Applies to False Advertising Claims, Nat'L L.J., May 13, 2002, at $\mathrm{C23,}$ available at http://www.rkmc.com/Lanham_Act_Also_Applies_to_False_Advertising_Claims.htm.

Implicitly misleading claims are probably harder to prove.

${ }^{46} 15$ U.S.C. $\$ 1125(\mathrm{a})(1)(\mathrm{B})$

${ }^{47}$ Advertisement Definition, Merriam-Webster (italics omitted), http://www.merriamwebster.com/dictionary/advertisement (last visited Apr. 10, 2011); see also Global Telesystems, Inc. v. KPNQwest, N.V., 151 F. Supp. 2d 478, 483 (S.D.N.Y 2001) (citing a dictionary definition to define advertisement). 
in part to regulate the use of approved medications in pediatric populations. ${ }^{48}$ In previous work, I described the serious medical consequences of pharmaceutical companies failing to disclose information regarding adverse effects in pediatric populations or failing to conduct clinical studies of drugs used in pediatric populations. ${ }^{49}$ In addition, the FDAAA now requires that clinical trials regarding life-threatening diseases be registered in a national registry. ${ }^{50}$ The 2007 additions and safeguards in the FDAAA are limited in that they only address the public disclosure of certain categories of clinical trials. Some misleading industry publications, however, may not be in these categories.

An obvious defense from the industry to any claim described above will be that industry publications are protected by the First Amendment, similar to the protections granted to scientific publications in general. ${ }^{51}$ Yet, although it is true that the law does protect scientific publications under the First Amendment due to the recognition that some scientific theories will be proposed and ultimately prove incorrect, it is also recognized and accepted that this type of collaboration and dissemination is required for scientific advancement. Importantly, much of the scientific literature is peer-reviewed, thus the scientific community self-patrols for reasonable theories.

The difference between the First Amendment protection of scientific publications in general and the industry publications at issue in this article is that the industry publications are intentionally misleading in order for the company to make money. As discussed in Part IV below, these publications may not be afforded full First Amendment protection; rather, they may be subject to the same speech regulations as commercial speech.

\section{PROPOSED SOLUTIONS TO PROTECT SCIENTIFIC INTEGRITY}

At present, no regulations exist that fully combat the problem of the dissemination of misleading or biased industry publications. The government has a substantial interest in protecting the health and welfare of its citizens. In addition, scientific integrity is called into question if the failure to report negative results from clinical trials is used to move science in the wrong direction. The public will begin to mistrust scientists, but it will not fully understand what is at the root of the problem - that is, the economic interests of pharmaceutical companies, whose economic interests may supersede health and safety. ${ }^{52}$ Described below are policy regulations aimed at addressing misleading or biased publications.

${ }^{48}$ FDAAA $\$ \S 401-02,501-02,121$ Stat. 823, 866, 876 (reauthorization of the Pediatric Research Equity Act and the Best Pharmaceuticals for Children Act).

${ }^{49}$ Sax, supra note 26 , at 71-75.

${ }^{50}$ Expanded Clinical Trial Registry Data Bank, Pub. L. No. 110-85, § 801(a)(2)(C), 121 Stat. 907 (2007)

${ }^{51}$ See, e.g., United States v. Caronia, 576 F. Supp. 2d 385, 395 (E.D.N.Y. 2008) (Scientific and academic speech are "at the core of the First Amendment and, therefore, should receive the highest constitutional protection as pure speech.").

${ }^{52}$ See, e.g., Hopkins v. Dow Corning Corp., 33 F.3d 1116 (9th Cir. 1994). 


\section{A. Trial Registration}

Trial registry, which has been called for by others, appears to be an effective mechanism to ensure that information is publicly available. ${ }^{53}$ Every clinical trial would be maintained on a clinical trial registry. Any publication that includes a clinical trial would have to cite to its registered identification number. This resolves the problems that stem from our working hypothetical. With a trial registry, even if a company decides to publish only the first six months of the study, the company would have to include a reference to its trial registry number. ${ }^{54}$ Once the scientist views the registry, the scientist will be able to see that the company conducted a one-year trial, but only published results from the first six months. Armed with knowledge that the company was trying to hide, the scientist can then critically evaluate the impact of the results. That is, the scientist will be skeptical of the results because the scientist now knows that the company is not reporting the full trial. The same applies to clinicians and policymakers. In essence, it would inhibit and prohibit companies from only making positive results available. The study design would always be available.

Congress attempted to promote the registry of clinical trials. In 2005 and again in 2007, Senator Chris Dodd introduced the Fair Access to Clinical Trial (FACT) Act. ${ }^{55}$ The FACT Act proposed and expanded a user-friendly database for clinical trials. ${ }^{56}$ Nevertheless, the FACT Act was unclear as to whether it required that all clinical trials be registered or instead was limited to the mandatory registration of trials that were aimed at treating life-threatening conditions. ${ }^{57}$

In any event, the FACT Act did not become law. ${ }^{58}$ It is unclear whether the FACT Act would have resolved many of the issues of underreporting or reporting bias in pharmaceutical clinical trials, which is a major problem as evidenced by the scandal regarding the use of anti-depressant medications in children.$^{59}$ For example, during congressional committee hearings regarding

${ }^{53}$ See, e.g., Kay Dickerson \& Drummond Rennie, Registering Clinical Trials, 290 JAMA 516, 518 (2003); Ida Sim \& Don E. Detmer, Beyond Trial Registration: A Global Trial Bank for Clinical Trial Reporting, 2 PLoS MEd. 1090, 1090-92 (2005). Of note, required trial registry is not mandated for non-serious or non-life-threatening diseases. See Food and Drug Administration Modernization Act of 1997 § 113, 42 U.S.C. 282(i) (2006).

${ }^{54}$ Select peer reviewed medical journals require that a clinical trial be registered in order to publish in that journal. See Erin D. Williams, Cong. Research Serv., RL 32832, Clinical Trials Reporting and Publication 4 (2005). This does not, however, address the problem of industry publications in non-peer-reviewed publications.

${ }^{55} \mathrm{Id}$. at 5 (discussing S. 470, the Fair Access to Clinic Trials Act of 2005). The 2007 version was called the Fair Access to Clinical Trials Act of 2007, S. 467, 110th Cong. (2007) [hereinafter FACT Act 2007].

${ }^{56}$ Williams, supra note 54, at 5; FACT Act 2007, §§ 2(1)-(4).

${ }^{57}$ Williams, supra note 54, at 5; FACT Act 2007, \$ 3(a)(4) ("The registry shall include information for all clinical trials conducted to test the safety or effectiveness (including comparative effectiveness) of any drug, biological product, or device (including those drugs, biological products or devices approved or cleared by the Secretary) intended to treat serious or life-threatening diseases and conditions .....") (emphasis added). But see FACT Act 2007 § 3 (a)(4) ("The database shall include information for all clinical trials conducted to test the safety or effectiveness (including comparative effectiveness) of any drug, biologic product, or device....”)

See $\quad$ S. $\quad 467: \quad$ FACT Act, $\quad$ Govtrack.us, http://www.govtrack.us/congress/bill.xpd?bill=s110-467 (last visited Apr. 14, 2011).

${ }^{59}$ See Sax, supra note 26 , at 76-78. 
antidepressant clinical studies in pediatric populations, members of Congress learned that the FDA knew of studies that demonstrated that certain antidepressant drugs were ineffective in pediatric populations; however, only a small number of these studies were published..$^{60}$ A comprehensive plan that includes the registration of all clinical trials and publication requirements is needed to resolve multiple issues with the reporting by the pharmaceutical industry.

Even if Congress passes a requirement for a national registry, registry alone will not resolve all gamesmanship. Rather, the FDA can step in to expand programs that it already has to regulate misleading publications.

\section{B. New Proposal: An Expanded Truth in Marketing Act}

\section{Existing Regulation}

The FDA has begun to crack down on false and misleading direct-toconsumer advertising. The FDA is, in part, using the FDAAA, which amended the Federal Food, Drug, and Cosmetic Act (FDCA) to include provisions regulating direct-to-consumer advertisements. ${ }^{61}$ The FDAAA grants the FDA the authority to preview any television advertisements for a drug prior to dissemination of the commercial to the public. ${ }^{62}$ If a party disseminates or causes to be disseminated a direct-to-consumer advertisement that is false or misleading, the FDAAA permits the FDA to impose a civil penalty. ${ }^{63}$ These FDAAA provisions are limited to addressing direct-to-consumer advertising. It is not clear that this could or would include scientific publications in the scientific or medical literature because scientific publications may not fall under direct-to-consumer advertising. In any event, that the FDA has authority to regulate false or misleading direct-to-consumer advertising demonstrates that the FDA could, with appropriate legislation, also regulate false or misleading scientific publications by some members of industry. ${ }^{64}$

In addition to the statutory language of the FDAAA, the FDA has a program, the Bad Ad Program, which facilitates the reporting of violations in: (1) sales representatives' presentations; (2) speaker program presentations; (3) TV and radio advertisements; and (4) all written or printed prescription drug promotional materials. ${ }^{65}$ Types of violations include: (1) omitting or downplaying risk; (2) overstating the effectiveness; (3) promoting off-label, or

${ }^{60} \mathrm{Id}$. at 74-75 (citing and discussing the hearings on antidepressant pediatric trials).

${ }^{61}$ FDAAA $\$$ 901-03, 121 Stat. 823, 939-43.

${ }^{62} I d . \$ 902$ (a), 121 Stat. 939 ("The secretary may require the submission of any television advertisement for a drug (including any script, story board, rough, or a completed video production of the television advertisement) to the Secretary for review under this section not later than 45 days before dissemination of the television advertisement.”)

${ }^{63}$ Id. $\$ 902$ (g), 121 Stat. 940.

${ }^{64}$ As described in Part III below, the FDA should be able to regulate the content of the industry publications so long as the publications are deemed commercial speech and any regulation does not violate the test articulated in Central Hudson. See Cent. Hudson Gas \& Electric Corp. v. Pub. Serv. Comm'n of N.Y., 447 U.S. 557 (1980).

65 FDA, Truthful Prescription Drug Advertising and Promotion (Bad Ad Program), http://www.fda.gov/Drugs/GuidanceComplianceRegulatoryInformation/Surveillance/DrugM arketingAdvertisingandCommunications/ucm209384.htm (last updated Mar. 31, 2011). 
unapproved, uses; and (4) misleading drug comparisons. ${ }^{66}$ The Bad Ad Program is a step in the right direction, although it is limited in that it relies on the reporting by others of potential violations. Also, it is limited because it focuses on presentations, advertisements and promotional materials. It does not explicitly include scientific publications, which are not necessarily clearly promotional. Furthermore, it is an outreach program administered by the FDA. As described in the Bad Ad Program, the FDA may be able to bring an enforcement action against a potential violator, but it is not a regulation that contains a private cause of action. ${ }^{67}$ That is, the Bad Ad Program may not be strong enough medicine to crack down on the wide variety of misleading tactics employed by the pharmaceutical companies.

The FDAAA prohibitions and the Bad Ad Program demonstrate that the FDA is concerned about the promotion and dissemination of misleading information by pharmaceutical companies. But, direct-to-consumer advertising is not the only way that pharmaceutical companies exert influence. Publications in scientific and medical journals, which this article refers to as indirect-to-consumer advertisements, can impact scientific progress and policies and have direct consequences for the public. In addition, the FDAAA regulations do not address a private cause of action, which may be a way to further clamp down on misleading publications.

\section{A Proposed Expansion}

This article proposes the introduction of a regulation to address the problem of misleading industry publications - the Truth in Marketing (TIM) Act. This new regulation should promote transparency and address the following areas:

(1) if the pharmaceutical company decides to end a clinical trial early, then any publication of the early parts of the clinical trial must include a notice that the clinical trial ended early;

(2) if the pharmaceutical company obtains any data from any portion of a clinical trial suggesting that the drug may cause harm at any time or if the data indicate that follow-up studies are necessary, this information must be included in any publication;

(3) if the pharmaceutical company obtains any data from any portion of a clinical trial suggesting that the drug is safe and effective, but does not offer therapeutic advantages over standard treatment, this information must be included in any publication;

(4) if a pharmaceutical company obtains any data that is contrary to or inconsistent with the reported conclusion(s) in a publication that a reasonable person in the scientific community would draw, that data must be included in any publication; and 
(5) a private cause of action can be brought for the violation of the provisions of this regulation if the FDA fails to diligently prosecute the violation in question. ${ }^{68}$

Violators of TIM should face steep monetary penalties. If the monetary penalties do not deter-that is, the same pharmaceutical company is a repeat offender-the FDA should be competent to issue an injunction that prohibits the pharmaceutical company from conducting any clinical trials or submitting applications for new drugs or devices for a specified period of time.

To determine the penalties for violation of TIM, the FDA should utilize economics to maximize deterrence. In brief, if one applies a traditional rational actor model, the formula that the pharmaceutical company will use when contemplating publishing biased or misleading information is whether the value of noncompliance is greater or less than the economic savings associated with noncompliance, minus the likelihood the violation will be detected, times the expected fine if the noncompliance is detected. ${ }^{69}$ If the pharmaceutical company is a rational actor, then it will comply with the regulation when the expected value of noncompliance is negative. If the expected value of noncompliance is positive, then the rational pharmaceutical company will ignore the regulation and violate the law because the incentives create a regime where it is cheaper for them to ignore the law. ${ }^{70}$ To successfully deter misleading industry publications, the FDA will need to research and assign values to the variables in order to establish the appropriate monetary penalties.

The proposal of a new FDA regulation that companies must comply with will face opposition. Often, FDA regulations suffer from many of the same complaints as those that surround Environmental Protection Agency restrictions; that is, the rules are complex and difficult to understand, making compliance difficult. ${ }^{71}$ It is likely that any attempt by the FDA to restrict the publication of misleading information will face similar challenges. This does not mean, however, that the ability of pharmaceutical companies to publish partial truths that have the adverse consequence of misleading the medical community, politicians, and the public should be unchecked.

\section{THE COMMERCIAL SPEECH DOCTRINE APPLIED TO MISLEADING INDUSTRY PUBLICATIONS}

The above proposals, trial registry and the TIM Act, arguably place constraints on industry's speech. Industry publications, as described above, may be subject to the commercial speech doctrine. Although described in detail in the legal scholarship, a brief synopsis of the commercial speech

${ }^{68}$ Cf. David Spence, The Shadow of the Rational Polluter: Rethinking the Role of the Rational Actor Model in Environmental Law, 89 CAL. L. Rev. 917, 940 (2001) ("Most environmental statutes bar citizens from proceeding if the government is diligently prosecuting the violations in question.").

${ }^{69} \mathrm{Id}$. at 920 (demonstrating this formula for prospective violators of environmental laws). The underlying rationale of environmental law can be applied to the FDA because the Environmental Protection Agency and FDA are both large regulatory regimes.

${ }^{70} I d$. at 921.

${ }^{71} \mathrm{Id}$. at 931 . 
doctrine as applicable to the issues raised in this article is appropriate here. ${ }^{72}$ After this brief summary, this article discusses how the commercial speech doctrine may be applied to misleading industry publications. Finally, this part discusses how any regulations must satisfy the commercial speech doctrine framework in order to withstand judicial scrutiny.

\section{A. Commercial Speech Doctrine: A Brief Overview}

In the landmark case Virginia State Board of Pharmacy v. Virginia Citizens Consumer Council, the Supreme Court articulated that commercial speech is protected by the First Amendment, but that the speech remains subject to permissible regulations. ${ }^{73}$ The Court provided that " $[\mathrm{u}]$ ntruthful speech, commercial or otherwise, has never been protected for its own sake."74 In Virginia State Board, the Court acknowledged that a state may regulate commercial speech that is provably false, deceptive, or misleading. ${ }^{75}$

In Central Hudson Gas \& Electric Corp. v. Public Service Commission of New York, the Court again acknowledged that commercial speech may be afforded a lesser protection than other forms of "constitutionally guaranteed expression." ${ }^{.76}$ In recognition of this, the Court stated that "[t]he government may ban forms of communication more likely to deceive the public than to inform it." 77 However, any restriction of expression must be carefully designed. ${ }^{78}$

Because it determines the rigor of review, a characterization must be made as to whether the speech in question is commercial or non-commercial. Regulations aimed at non-commercial, fully-protected speech receive strict scrutiny, whereas laws addressing commercial speech may regulate it based on content. ${ }^{79}$ In short, the characterization of the speech determines whether the speech is fully protected under the First Amendment, or whether the government has more leeway in regulating the speech. To make a determination as to whether the speech is commercial, a court looks to: (1) whether the speech is an advertisement; (2) whether the speech refers to a specific product; and (3) whether the speaker has an economic motivation. ${ }^{80}$

${ }^{72}$ See, e.g., C. Edwin Baker, Paternalism, Politics, and Citizen Freedom: The Commercial Speech Quandary in Nike, 54 CASE W. Res. L. Rev. 1161 (2003-04); Glenn C. Smith, Avoiding Awkward Alchemy-In the Off-Label Drug Context and Beyond: Fully Protected Independent Research Should Not Transmogrify into Mere Commercial Speech Just Because Product Manufacturers Distribute It, 34 Wake Forest L. Rev. 963, 988-1016 (1999).

${ }_{73}$ Va. State Bd. of Pharmacy v. Va. Citizens Consumer Council, Inc., 425 U.S. 748, 770 (1976).

${ }^{74} I d$. at 771

${ }^{75}$ See id.

${ }^{76}$ Cent. Hudson Gas \& Electric Corp. v. Pub. Serv. Comm'n of N.Y., 447 U.S. 557, 563 (1980).

${ }^{77} I d$.

${ }^{78} \mathrm{Id}$. at 567

${ }^{79}$ See, e.g., United States v. Caronia, 576 F. Supp. 2d 385, 395 (E.D.N.Y. 2008) (describing that speech protected by the First Amendment receives the highest constitutional protection).

${ }^{80} I d$. at 396; see also Bolger v. Youngs Drug Prod. Corp., 463 U.S. 60, 67 \& n.14 (1983) (describing that the "combination of all these characteristics" provides strong support to characterize speech as commercial, but that the characteristics of all three do not have to be present in order for the speech to be commercial). 
Once speech is deemed to be commercial, the Court articulated a fourpart analysis to determine when the government may restrict it. ${ }^{81}$ First, the speech "must concern lawful activity and not be misleading." ${ }^{82}$ Second, the Court must ask whether the asserted government interest in regulating the speech is substantial. ${ }^{83}$ Third, it must be determined that the regulation advances the asserted government interest. ${ }^{84}$ Finally, the Court will determine whether the government regulation is more extensive than necessary to serve the state interest. ${ }^{85}$

Of note, if the commercial speech concerns unlawful activity or is misleading, the speech is not protected. ${ }^{86}$ To determine whether speech is misleading, it must be more likely to deceive the public than to inform it. ${ }^{87}$ If the commercial speech is misleading, the analysis ends there. If, however, the commercial speech concerns lawful activity and is not clearly misleading, then a court will continue to steps two through four of the Central Hudson test. $^{88}$

\section{B. The Commercial Speech Doctrine Applied to Misleading or Biased Industry Publications}

An application of the facts from our working hypothetical to the commercial speech jurisprudence demonstrates that some industry publications may be subject to the commercial speech doctrine. Here, the industry publication hypothetical that advances the use of its drug over the standard treatment appears to satisfy the requirements of commercial speech.

First, an industry publication is a promotion of a new drug. It is unclear whether an industry publication is an advertisement in a classical sense. As mentioned above, advertisement is defined as "a public notice; especially: one published in the press or broadcast over the air." ${ }^{89}$ In the general sense, one usually thinks of advertisements as TV commercials, billboards, or ads in a magazine. This article refers to these types of advertising as direct-toconsumer advertising. Industry publications in the medical or scientific literature that promote products to scientists and physicians do not appear to fall under the classical definition of advertisement because they are not ads in a magazine or quick clips on the television. However, the publication nonetheless communicates information to the scientific and medical community and public for the advancement of the use of a particular therapy and so it has some of the characteristics of the term advertisement. Put differently, the promotion of the drugs to doctors, who ultimately prescribe

\footnotetext{
${ }^{81}$ Central Hudson, 447 U.S. at 566.

${ }^{82} I d$.

${ }^{83} I d$.

${ }^{84} I d$.

${ }^{85} I d$.

${ }^{86}$ United States v. Caronia, 576 F. Supp. 2d 385, 396-97 (E.D.N.Y. 2008).

${ }^{87} \mathrm{Id}$. at 397 (quoting Wash. Legal Found. v. Friedman, 13 F. Supp. 2d 51, 74-75 (D.D.C. 1998)).

${ }^{88} I d$. This summary of the commercial speech doctrine is cursory. Legal scholarship in this area analyzes the clarity or lack thereof in utilizing the commercial speech doctrine. Indeed, even decisions in lower courts demonstrate uncertainty when applying the commercial speech doctrine. See generally Smith, supra note 72, at 988-1016.

${ }^{89}$ Advertisement, supra note 47; see also Global Telesystems, Inc. v. KPNQwest, N.V., 151 F. Supp. 2d 478, 483 (S.D.N.Y. 2001) (citing a dictionary definition to define advertisement).
} 
the medication to patients, is what makes this speech a promotion of a particular product..$^{90}$ This article utilizes the term, indirect-to-consumer advertising, to describe the promotion of an industry's product in the scientific or medical literature to the medical community for use in the general public or to entice academic scientists to use federal funding dollars to conduct research. Second, the publication refers to the specific drug manufactured by the company, and, finally, the company has an economic motivation to promote the use of its drug. ${ }^{91}$

A potential counterargument to the above analysis that deems industry publications commercial speech is that "academic and scientific" speech are afforded full First Amendment protection, and that industry publications fall within "academic and scientific" speech. ${ }^{92}$ This is a weak counterargument, however, if the industry publication is placed in a non-peer reviewed journal, the publication deliberately omits important scientific information and the purpose of the publication is to reach the medical community in order to promote the sale of the product. ${ }^{93}$ The reason that scientific and academic speech is fully protected is to let ideas flow freely within a community to allow science to progress and allow for paradigm shifts. Industry publications, which are not peer reviewed or intentionally leave out important information that would change the conclusions, do not promote the free flow of ideas or allow for paradigm shifts. Here, the industry publication is specifically describing the advantages of its particular product in an effort to increase sales and revenues related to its product. Applying facts from our working hypothetical, it is clear that the purposes of the publications are to promote the use and sales specifically of the company's new product, which is why it may be characterized as commercial speech. ${ }^{94}$ This may mislead the scientific community, the public at large, and policymakers.

If the publications in our working hypothetical are deemed commercial speech, an analysis must next determine whether the government may restrict the speech. ${ }^{95}$ The first prong of the Central Hudson test is to determine whether the speech concerns lawful activity and is not misleading. ${ }^{96}$ Misleading is defined as "likely to mislead a reasonable consumer acting

${ }^{90}$ See IMS Health Inc. v. Ayotte, 550 F.3d 42, 45, 54 (2008) (finding valid a restriction of the ability of pharmaceutical representatives to utilize physicians' prescribing history for use in detailing).

${ }^{91}$ See Cent. Hudson Gas \& Electric Corp. v. Pub. Serv. Comm'n of N.Y., 447 U.S. 557, 56163 (1980).

92 See, e.g., Caronia, 576 F. Supp. 2d at 395 (addressing arguments as to whether "promotional activities amounted to scientific and academic speech, which resides at the core of the First Amendment”).

${ }^{93}$ See $i d$. ("[A]lthough the prescription drug industry presented a different context than traditional forms of consumer advertising, it was clear that the speech to doctors was intended to drive sales of products because 'to the extent that physicians are the gatekeepers to sales, the marketing efforts must be directed at them."' (citation omitted)).

${ }^{94}$ If the speech was not deemed commercial, the question then arises as to whether the TIM Act regulates protected speech and could survive strict scrutiny. I thank my colleague, Larry Benner, for raising this important issue. An argument can be made that the government has a compelling interest to regulate the conduct of the speech at issue in this article and that the TIM Act is narrowly tailored to this interest.

${ }^{95}$ Central Hudson, 447 U.S. at 566.

${ }^{96}$ Id. 
reasonably under the circumstances." 97 Here, an industry publication that intentionally omits data that demonstrates that the new drug does not offer better therapeutic treatment after one year when compared to the standard treatment is misleading to the reader. ${ }^{98}$ For example, a prescribing physician who reads that the new drug offers greater therapeutic advantage than the standard treatment may recommend that their patients use the new drug over standard treatment. This will increase the sales for the pharmaceutical company, but the new treatment does not offer the patient advantages over the long-term. It is reasonable to assume that a physician would want to use what he considers to be the best drug in the treatment of the patients, and an industry publication that omits the long-term data may influence the physician to prescribe the new drug.

Furthermore, if an additional fact is added to our working hypothetical, such as that the pharmaceutical company provides pens and pads of paper to physicians with the company logo, this might create an additional influence on the prescribing physician to prescribe the new drug. Studies have shown that even small gifts can have the impact of unduly influencing the decisions that physicians make in prescribing medications. ${ }^{99}$ The point is that over the years, the pharmaceutical industry has utilized tactics that promote their products and increase the sale of their drugs. Many of these tactics impact the way physicians prescribe drugs, even on an unconscious level.

In sum, by publishing only the results from the first six months of the trial, which demonstrates that the new drug is superior to the standard treatment, the company is misleading scientists, clinicians, and the public to believe that the new drug offers greater therapeutic advantages to treat a longterm cholesterol problem than the standard treatment. This publication is misleading. Once there is a determination that the speech is misleading, the analysis ends there.

One problem with characterizing the speech in our working hypothetical as misleading is that a court may require an affirmative statement in order for the speech to be considered misleading. The misleading nature of the speech in the working hypothetical is misleading because there is an omission of data. In other words, the inclusion of the long-term data would lead a reasonable scientific person to conclude that the new drug does not offer any therapeutic advantage over standard therapy, while by the omission of that data, the reasonable scientific person is misled to believe that the industry's conclusion(s) are taken from the six-month data, which indicate that the new treatment may offer better results than the standard therapy. For this reason, an analysis of the other three elements of the Central Hudson test is critical.

${ }^{97}$ Cohen v. JP Morgan Chase \& Co., 498 F.3d 111, 126 (2d Cir. 2007) (citing Oswego Laborers' Local 214 Pension Fund v. Marine Midland Bank, 647 N.E.2d 741, 745 (N.Y. 1995)).

${ }^{98}$ See Central Hudson, 447 U.S. at 566.

99 Ass'n of Am. Med. Colls., Industry Funding of Medical Education: Report of AN AAMC TASK Force 4 (2008), www.aamc.org/publications (search publications: Industry Funding) ("Supplementing the robust psychosocial evidence regarding the effect of gifts on physician decision making, recent neurobiological studies document that inherent biological processes can cause individuals to respond reciprocally-and typically unconsciously-to relationships involving even simple gifts, sponsorships, or the development of personal relationships.”). 
The second prong of the Central Hudson test analyzes whether the government has a substantial interest in regulating the speech. ${ }^{100}$ Here, the FDA has a substantial interest in regulating the use of prescription drugs in order to protect the public. ${ }^{101}$ All clinical trial protocols to study an unapproved drug or an approved product for a new indication must be approved by the FDA, via the Investigational New Drug Application. ${ }^{102}$ In order to obtain FDA drug approval, the results of clinical trials must be reported to the FDA. ${ }^{103}$ The FDA's scheme that regulates clinical trials with the purpose of having public health and safety at the forefront may be thwarted by publications that fail to fully report clinical trials. That is, even though the pharmaceutical company must report results from clinical trials to the FDA so that the FDA can assess the results and make decisions that consider the public's health and safety, by reporting only a portion of the results from the clinical trials to the medical community directly, this can chip away at the FDA's purpose of protecting the public. The government has a substantial interest in requiring full disclosure of clinical trial data to the scientific and medical communities and the public such that unbiased and non-misleading information reaches the public to ensure public health and safety.

The National Institutes of Health (NIH) also has a substantial interest in the funding of scientific research. ${ }^{104}$ If a scientist submits a grant application that includes proposals for research that rely on industry publications that conceal data, the scientist may be on a wild-goose chase, with the government funding the effort. This has the negative effects of wasting valuable scientific resources as well as costs to the taxpayers who fund academic research. In sum, the government has a substantial interest in protecting the health and welfare of its citizens.

${ }^{100}$ Central Hudson, 447 U.S. at 566.

101 Centers छ Offices, FDA (last updated Feb. 15, 2011), http://www.fda.gov/AboutFDA/CentersOffices/default.htm ("The FDA is responsible for protecting the public health by assuring the safety, efficacy, and security of human and veterinary drugs, biological products, medical devices, our nation's food supply, cosmetics, and products that emit radiation, and by regulating the manufacture, marketing, and distribution of tobacco products"); see also Thompson v. W. States Med. Ctr., 535 U.S. 357, 368-69 (2002) (describing the Government's interest under the Food and Drug Administration Modernization Act (FDAMA) and Food, Drug, and Cosmetic Act (FDCA)).

102 Investigational New Drug Application, FDA (last updated Nov. 5, 2010), http://www.fda.gov/Drugs/DevelopmentApprovalProcess/HowDrugsareDevelopedandApprov ed/ApprovalApplications/InvestigationalNewDrugINDApplication/default.htm ～"Detailed protocols for proposed clinical studies to assess whether the initial-phase trials will expose subjects to unnecessary risks.").

103 New Drug Application, Introduction, FDA (last updated Aug. 20, 2010) http://www.fda.gov/Drugs/DevelopmentApprovalProcess/HowDrugsareDevelopedandApprov ed/ApprovalApplications/NewDrugApplicationNDA/default.htm ("The documentation required in an NDA is supposed to tell the drug's whole story, including what happened during the clinical tests, what the ingredients of the drug are, the results of the animal studies, how the drug behaves in the body, and how it is manufactured, processed and packaged.").

${ }_{104}$ NIH \& Clinical Research: About Us, NaT'L Insts. OF Health, http://clinicalresearch.nih.gov/about.html (last visited Apr. 14, 2011) ("The National Institutes of Health (NIH), a part of the U.S. Department of Health and Human Services, is the primary Federal agency for conducting and supporting medical research.”). 
The third element in the Central Hudson test is that the regulation advances the asserted government interest. ${ }^{105}$ Here, it is not clear that any federal regulation that is in effect at this time requires a publication to include all of the results of all clinical trials. The Food and Drug Administration Modernization Act of 1997 only requires the public registration of clinical trials that address life-threatening conditions. ${ }^{106}$ Again, for drug approval the FDA requires that a company apply to conduct a clinical trial and report the results to the FDA; but nothing in the regulations require that the company publicly report the results. ${ }^{107}$ This lack of regulation, in part, may allow a loophole for industry to underreport negative results of clinical trials in publications. As described in Part III, the TIM Act would close the current loophole. In sum, the TIM Act directly advances the government interest of protecting the health and safety of the public because it would require the disclosure in scientific and medical literature of data that may lead a reasonable scientific reviewer to conclude differently from the stated conclusions in the publication.

Finally, a determination is made as to whether the government regulation is more extensive than necessary to serve the state interest. ${ }^{108}$ Again, at this time, no regulation addresses the requirement of dissemination of negative results of all clinical trials. But if the policy objectives of the TIM Act are turned into a regulation, this regulation must comply with the requirements of the Central Hudson test.

In sum, no current regulation adequately regulates misleading or biased industry publications in scientific and medical literature. The government has a substantial interest in protecting the public health and should enact regulations to address misleading or biased publications. Mandatory trial registry and the TIM Act are strong starting points to address misleading and biased industry publications, but any new policy must be wary of a claim that the regulation violates First Amendment rights. This symposium is an

${ }^{105}$ Central Hudson, 447 U.S. at 566.

${ }^{106}$ Food and Drug Administration Modernization Act of 1997 \$ 113, 42 U.S.C. 282(i) (2006); see Guidance for Industry, Information Program on Clinical Trials for Serious or LifeThreatening Diseases and Condition 2002), http://www.fda.gov/downloads/RegulatoryInformation/Guidances/UCM126838.pdf ("Section 113 of the Modernization Act creates a public resource for information on studies of drugs, including biological drug products, to treat serious or life-threatening diseases and conditions conducted under FDA's investigational new drug (IND) regulations (21 CFR part 312).”).

107 See Erick H. Turner, A Taxpayer-Funded Clinical Trials Registry and Results Database, 1 PLoS MED. 180, 180-81 (2004) (describing the NDA process); New Drug Application, Introduction, supra note 103.

${ }^{108}$ Central Hudson, 447 U.S. at 566. Another issue that may need to be addressed is whether there are means by which the government can regulate the dissemination of results in a way that does not affect speech. I thank my colleague, Larry Benner, for raising this important point. See, e.g., Thompson v. W. States Med. Ctr., 535 U.S. 357, 371-73 (2002) (addressing the issue of ways the "Government could achieve its interests in a manner that does not restrict speech, or that restricts less speech"). For example, a different approach would be to have the government independently run all the clinical trials for any new drug and then report the results. In this way, the process of reporting clinical trial information would be controlled in all respects by the government. The problem with this type of solution is that it is probably economically and logistically impossible. Since there is a private market for clinical trials, it might be considered economic waste to have the government commandeer all parts of all clinical trials. While this would avoid the First Amendment problem, it seems, for practical purposes, impossible. 
important place to continue the dialogue of the increasing role of the commercial speech doctrine in health regulation.

\section{CONCLUSION}

Misleading or biased publications reporting results of clinical trials cannot go unchecked due to the potential for harmful effects on scientific integrity and public health. The commercial speech doctrine allows the government to regulate some speech if there is a defined purpose. Thus, the growing role of the commercial speech doctrine in health regulation - the important topic of this symposium -is the launching point for the government to regulate misleading or biased indirect-to-consumer publications.

The current policies of the FDA are a good starting point, but these regulations do not necessarily reach misleading industry publications that are not clearly advertising. This article proposes the expansion of current FDA policies to cast a wider net to include indirect-to-consumer marketing. Policymakers can learn from publicized stories over the past few decadessuch as the tobacco industry tactics and breast implant cases-to draft regulations to ensure that the scientific and medical communities, policymakers, and the public have accurate information in order to make the best healthcare decisions. In this way, scientific integrity-which benefits the public-can be protected and continue to provide improved healthcare services to the public. 